\title{
Stent-graft treatment of an ascending aortic false aneurysm after surgical aortic valve replacement
}

\author{
From the ${ }^{a}$ Department of Cardiovascular Surgery, German Heart Center Munich, Technische Universität \\ München, Munich, Germany; and ${ }^{b}$ Insure (Institute for Translational Cardiac Surgery), Department of Cardio- \\ vascular Surgery, German Heart Center Munich at the Technical University of Munich, Munich, Germany. \\ Disclosures: Authors have nothing to disclose with regard to commercial support. \\ Received for publication Feb 8, 2018; revisions received May 7, 2018; accepted for publication May 14, 2018; \\ available ahead of print June 27, 2018 \\ Address for reprints: Hendrik Ruge, MD, Department for Cardiovascular Surgery, German Heart Center Munich, \\ Lazarettsrasse 36, 80636 Munich, Germany (E-mail: ruge@dhm.mhn.de). \\ J Thorac Cardiovasc Surg 2018; 156:e183-5 \\ $0022-5223 / \$ 36.00$ \\ Copyright (c) 2018 by The American Association for Thoracic Surgery \\ https://doi.org/10.1016/j.jtcvs.2018.05.063
}

Video clip is available online.

Stent grafting of the ascending aorta represents nonstandard treatment option, only performed in selected cases in which conventional surgery is assumed to be impossible or to pose an intolerably high risk.

\section{CASE DESCRIPTION}

A 73-year-old woman presented in New York Heart Association functional class III as a result of the degeneration of a 23-mm Sorin Mitroflow aortic valve prosthesis (LivaNova, PLC, London, United Kingdom) that had been implanted 6 years before admission. A preoperative computed tomographic scan of the thoracic aorta demonstrated a broken sternal wire at the midpart of the sternum, which had perforated the ascending aorta. Consequently, a 23 (wide) $\times 21$ (height) $\times 12$ (anteroposterior diameter)$\mathrm{mm}$ perfused false aneurysm of the ascending aorta had developed and stuck to the sternum. A dedicated team, experienced in aortic surgery and transcatheter aortic valve replacement, agreed after careful assessment that conventional surgery posed an increased operative risk, because a median resternotomy would have been possible only with deep hypothermic circulatory arrest of prolonged duration, carrying an increased risk of a severe neurologic deficit. In addition, severe impairment of ambulation from a previous complex lower leg fracture, with resulting permanent use of crutches, was unfavorable to recovery after resternotomy.

After detailed assessment of the computed tomographic scan, stent-graft treatment of the ascending aorta was determined to be a valuable option. The ascending aorta provided appropriate proximal and distal landing zones with appropriate distance to the coronary arteries and the supra-aortic vessels. A custom-made tapered Relay Plus

\section{DISCUSSION}

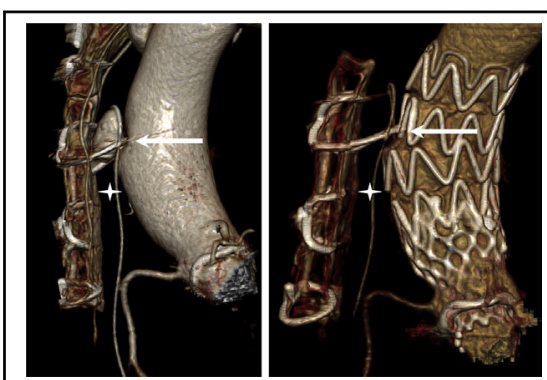

False aneurysm of the ascending aorta caused by broken sternal wire (white arrow).

Central Message

Stent grafting offers alternative treatment options to high-risk heart procedures, even for pathologies of the ascending aorta.

See Editorial Commentary page e 187

NBS stent graft (Bolton Medical, Barcelona, Spain), measuring $80 \mathrm{~mm}$ in length, $42 \mathrm{~mm}$ in proximal diameter, and $38 \mathrm{~mm}$ in distal diameter, was ordered for an elective interventional treatment.

In a hybrid surgical room, a transfemoral percutaneous valve-in-valve procedure with a 23-mm Medtronic Evolut R prosthesis (Medtronic, Minneapolis, Minn) was performed first. After removal of the deployment catheter, the Bolton Medical delivery system was inserted through the same femoral access. The covered stent graft was deployed in the ascending aorta under rapid pacing and fluoroscopic control. Angiography demonstrated proper exclusion of the false aneurysm, without any impairment of coronary and cerebrovascular perfusion (Figure 1). At discharge, the computed tomographic control confirmed a stable stent-graft position, with complete thrombosis of the false aneurysm. At 12 months of follow-up, the stent graft remained unchanged in position, without any signs of structural deterioration caused by the sternal wire (Video 1). Echocardiography demonstrated a mean gradient of $12 \mathrm{~mm} \mathrm{Hg}$ across the aortic valve prosthesis at discharge and a mean gradient of $6 \mathrm{~mm} \mathrm{Hg}$ across the aortic valve after 1 year, confirming a normal valve function according to the Valve Academic Research Consortium 2 (VARC-2) criteria.

Whereas endovascular stent grafts have nearly replaced conventional surgery for pathologies of the descending 

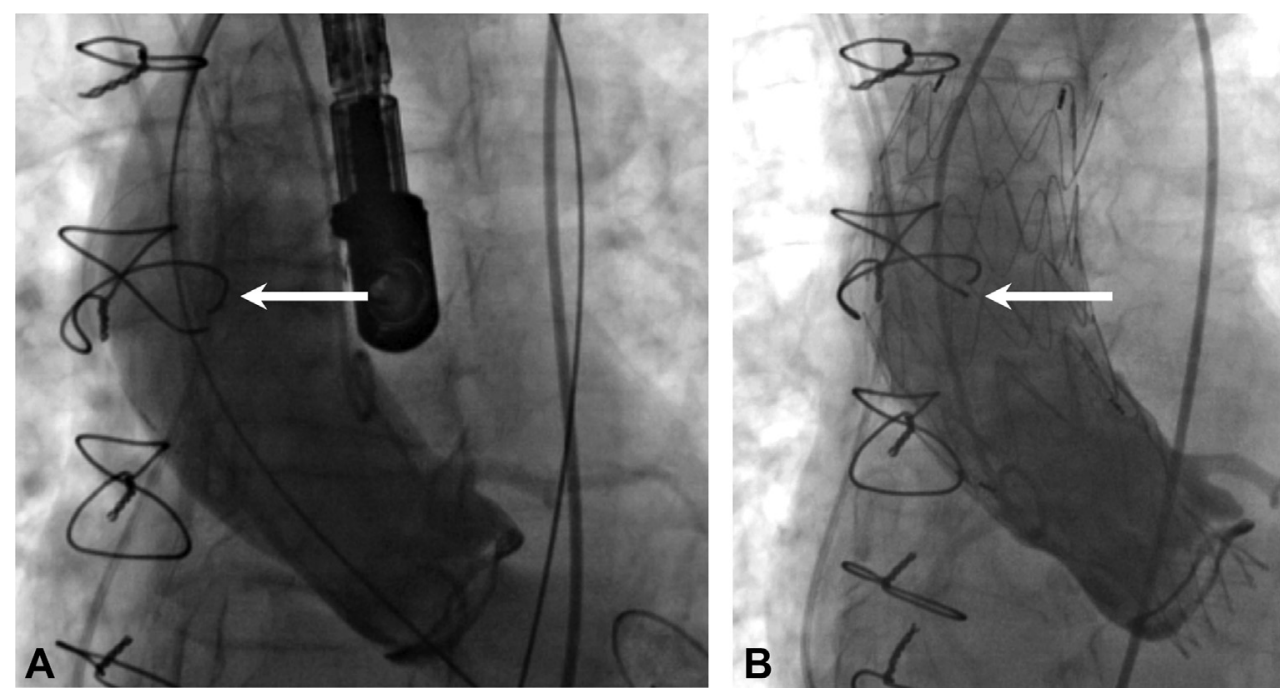

FIGURE 1. A, False aneurysm of the ascending aorta caused by the broken sternal wire. The white arrow indicates the broken sternal wire. B, The stent graft overlapping the first frame of the Medtronic Evolut R prosthesis (Medtronic, Minneapolis, Minn), with definite exclusion of the false aneurysm. The white star Central Figure indicates an epicardial pacemaker wire from the index procedure.

thoracic aorta, endovascular treatment of the ascending aorta is still a matter of anecdotal case reports or small patient series only. ${ }^{1-4}$ In-hospital mortalities of $6.7 \%$ to $14.2 \%$ and stroke rates between $3.3 \%$ and $14.2 \%$ have been reported for reoperations for mediastinal false aneurysm of the ascending aorta. $^{5-7}$ On the basis of our broad annual experience of 180 operations on the ascending aorta, an additional 50 aortic arch operations, and 600 transcatheter aortic valve replacement procedures, we chose an interventional treatment strategy after a careful operative

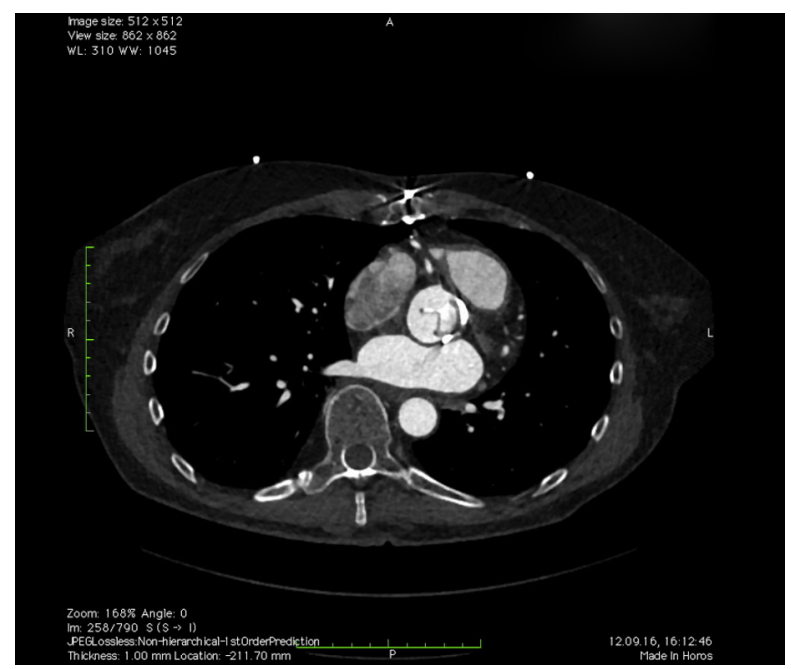

VIDEO 1. First, axial and volume-rendered computed tomographic runs show the false aneurysm. Aortic angiography confirms the proper position and sealing of the transcatheter heart valve, followed by stent-graft deployment. Finally, axial and volume-rendered computed tomographic runs show the final stent-graft position, excluding the false aneurysm. Video available at: https://www.jtcvs.org/article/S0022-5223(18)31489-2/fulltext. risk assessment and consideration of the patient's severe impairment in ambulation. The Society of Thoracic Surgeons predicted risk of mortality score of $2.5 \%$ only calculates the aortic valve reoperation and does not include the ascending aorta replacement in the calculations, thus providing only limited information for the reported procedure. The true inner diameter of a $23-\mathrm{mm}$ Sorin Mitroflow valve is $19 \mathrm{~mm}$. We chose a Medtronic Evolut R transcatheter heart valve, which allows a supra-annular valve position, to aim for low gradients after valve-in-valve transcatheter heart valve implantation into the small bioprosthetic valve ring.

At present, stent-graft treatment of the ascending aorta is restricted to elective procedures, because the devices have to be manufactured on a custom-made basis. A prerequisite of stent grafting of the ascending aorta is the presence of sufficient proximal and distal landing zones. An appropriate distance to the aortic valve and the coronary arteries is required proximally, and appropriate distance to the head vessels is required distally. In addition, the inner curvature of the ascending aorta is shorter than the outer curvature, a condition that has to be considered when choosing the appropriate graft dimensions in device planning. After computed tomographic assessment, the estimated time span between ordering and delivery of a device is about 3 weeks at best, illustrating that endovascular treatment of ascending aortic disease these days is restricted to elective procedures.

Although interventional treatment strategies offer alternatives to high-risk heart procedures even in the case of pathology of the ascending aorta, further device development is required to overcome the drawbacks in the lesser availability of the custom-made devices. 


\section{References}

1. Tsilimparis N, Debus ES, Oderich GS, Haulon S, Terp KA, Roeder B, et al. International experience with endovascular therapy of the ascending aorta with a dedicated endograft. J Vasc Surg. 2016;63:1476-82.

2. Preventza O, Henry MJ, Cheong BY, Coselli JS. Endovascular repair of the ascending aorta: when and how to implement the current technology. Ann Thorac Surg. 2014;97:1555-60.

3. Nienaber CA, Sakalihasan N, Clough RE, Aboukoura M, Mancuso E, Yeh JS, et al. Thoracic endovascular aortic repair (TEVAR) in proximal (type A) aortic dissection: ready for a broader application? J Thorac Cardiovasc Surg. 2017; 153:S3-11.
4. Gandet T, Alric P, Bommart S, Canaud L. Endovascular aortic repair of chronic ascending and arch aortic aneurysm. J Thorac Cardiovasc Surg. 2018; 153:e79-83.

5. Atik FA, Navia JL, Svensson LG, Vega PR, Feng J, Brizzio ME, et al. Surgical treatment of pseudoaneurysm of the thoracic aorta. J Thorac Cardiovasc Surg. 2006;132:379-85.e1.

6. Katsumata T, Moorjani N, Vaccari G, Westaby S. Mediastinal false aneurysm after thoracic aortic surgery. Ann Thorac Surg. 2000;70:547-52.

7. El Oumeiri B, Louagie Y, Buche M. Reoperation for ascending aorta false aneurysm using deep hypothermia and circulatory arrest. Interact Cardiovasc Thorac Surg. 2011;12:605-8. 